\title{
ENTRE O NASCIMENTO E A MORTE: REFLEXÕES DE VIVÊNCIAS DE CAMPO
}

BETWEEN BIRTH AND DEATH: REFLECTIONS OF FIELD EXPERIENCES

\author{
Natália Rejane Salim*; Glauce Cristine Ferreira Soares*; Regina \\ Szylit***; Cláudia Malinverni***; Dulce Maria Rosa Gualda*** \\ * Universidade Federal de São Carlos; ${ }^{* *}$ Maternidade Amador Aguiar.Osasco; * * \\ Universidade de São Paulo; nat.salim@ufscar.br; glaucesoares@yahoo.com.b; \\ szylit@usp.br; claudia.malinverni@usp.br; drgualda@usp.br
}

\begin{tabular}{|c|c|}
\hline Histori & Resumo \\
\hline Recibido: 2 & \multirow{6}{*}{$\begin{array}{l}\text { O nascimento e a morte, como eventos limite da vida, possuem pontos de conver- } \\
\text { gência. Discutir as formas pelas quais esses eventos acontecem nos serviços de } \\
\text { saúde e como impactam a vida das pessoas envolvidas é fundamental para a pro- } \\
\text { dução de cuidados. Esta reflexão tem como objetivo relatar e discutir os resultados } \\
\text { de duas investigações desenvolvidas em contextos de atenção ao parto e em uma } \\
\text { UTI neonatal. Refletir sobre o nascimento e a morte é essencial para a promoção } \\
\text { da atenção integral e humanizada em saúde. O exercício de práticas de cuidado } \\
\text { alicerçadas na humanização e nos direitos é capaz de produzir espaço de trocas, de } \\
\text { aprendizado e de vivências às famílias, aos profissionais, às mulheres e aos bebês } \\
\text { no interior dos serviços de saúde. }\end{array}$} \\
\hline $5-11-2019$ & \\
\hline Aceptado: 20-05-2020 & \\
\hline Publica & \\
\hline Palas & \\
\hline $\begin{array}{l}\text { Nascimento; Morte; } \\
\text { Integralidade em saúde; } \\
\text { Humanização; Empatia }\end{array}$ & \\
\hline
\end{tabular}

Abstract

Keywords

Birth; Death; Integrality in health; Humanization of work; Empathy
Birth and death as limiting events of life and have points of convergence. Discussing the ways these events take place within health services and how them impact people lives is critical to the production of care. This reflection aims to discuss points about the historical constructions and care practices involved in birth and death through experiences from the field of research in contexts of attention to childbirth and in a neonatal care unit. Reflecting on birth and death is essential for the promotion of comprehensive and humanized health care. The exercise of care practices based on humanization and rights is able to provide space for exchanges, learning, experiences within the health services for the family, professionals, women and babies.

Salim, Natália Rejane; Soares, Glauce Cristine Ferreira; Szylit, Regina; Malinverni, Cláudia \& Gualda, Dulce Maria Rosa (2021). Entre o nascimento e a morte: reflexões de vivências de campo. Athenea Digital, 21(2), e2629. https://doi.org/10.5565/rev/athenea.2629

\section{Introdução}

Podemos dizer que o nascimento e a morte são vivências limiares que marcam fronteiras no curso da vida. Neste artigo nos propomos a discutir a complexidade desses eventos caminhando pelos resultados de duas investigações que se dedicaram a olhar as práticas e as relações de cuidado, bem como relatar experiências de campo da primeira autora como meio de reflexão acerca da importância do acolhimento e da humanização no nascimento e nos eventos de adoecimento e de morte. Essas vivências são frutos do processo de coleta de dados em diferentes contextos de atenção ao parto e em uma unidade de terapia intensiva neonatal (UTIN). 
Primeiramente, apresentamos um breve histórico da prática médica que sustenta a nossa discussão. Em seguida, trazemos as vivências, memórias e experiências de investigação em diálogo com as perspectivas teóricas da pesquisa social.

O olhar sócio-histórico sobre o exercício da medicina nos leva a entender como concepções e práticas consideradas naturais para lidar com o nascer e com o morrer foram construídas e instituídas ao longo do tempo (Rohden, 2006). Autores como Michel Foucault (1976/2014) e Ivan Illich (1976), ao refletirem sobre como a regulação e o controle dos corpos permitiram a crescente apropriação dos modos de vida do homem pela medicina, evidenciaram a adesão das práticas médicas ao modelo biomédico e, consequentemente, a instituição do hospital como local espacial da doença e da morte.

Tal processo teve início em meados do século XVIII, quando o regime teocrático ocidental, que tinha entre seus objetivos a salvação das almas, começou a ser substituído por uma "somatocracia" que postula, entre outras tarefas, a intervenção estatal no cuidado do corpo, na saúde corporal e na relação entre doença e saúde (Foucault, 1978/1998; 2014). Depois disso, apontam Luiz Alberto Moreira Martins e Carlos Augusto Peixoto Junior (2009, p. 158), o médico e o biológico deixam de trabalhar no nível do indivíduo (do doente e suas doenças), passando a vida em seu conjunto a ser “objeto de preocupação do Estado, por meio da intervenção médica”. Daí emergeria, mais tarde, o conceito foucaultiano de biopoder.

Esse processo deu-se por dois polos de desenvolvimento, ambos vinculados a um conjunto de relações que envolvem o poder-saber, notadamente o médico. O primeiro aparece centrado no corpo, tomado como lócus de disciplinarização, o que o tornou uma máquina dócil e submissa que possibilitava o desenvolvimento e a propagação da força de trabalho indispensável ao desenvolvimento do sistema capitalista (Martins e Peixoto Junior, 2009). Disciplinado ao longo do tempo por sistemas de controle assegurados pelo procedimento de poder-saber, o corpo-máquina deu origem a uma anátomo-política do corpo humano. O segundo polo tem enfoque no corpo como espécie imbuída de mecanismos de vida, servindo como base dos processos fisiológicos. Assim, o poder passou a operar sobre os corpos através de dispositivos de vigilância e controle, o que incidiu diretamente nas práticas de saúde e relações de cuidado nos processos de nascimento, adoecimento e morte (Sousa e Meneses, 2010).

Em apertada síntese, esse processo implicou a medicalização da medicina, da sociedade e da população, sob quatro processos ligados à expansão do domínio do saber médico. A saber, o surgimento da autoridade médico-política e a instauração da medicina de Estado e da polícia médica; a ampliação dos domínios da medicina para além dos doentes e da doença, com a constituição da medicina urbana; a medicalização do 
hospital, ou seja, sua transformação em instrumento terapêutico; e, por fim, a criação de mecanismos de administração médica, tais como registro de dados, estabelecimento e comparação de estatísticas, entre outros (Foucault, 1978/2014; Martins e Peixoto Junior, 2009).

Nessa perspectiva, as práticas de saúde transformaram-se em dispositivos de controle dos corpos e dos eventos da vida. Essa mudança de contexto de cuidado demandou a inserção de novas práticas, novos atores e novas regras para o controle do nas cer e do morrer. Nesse processo, é particularmente importante o papel desempenhado pelo hospital geral, que passou de instituição de exclusão e de assistência, onde se misturavam diferentes tipos sociais excluídos - loucos, doentes e prostitutas, por exemplo -, a instrumento terapêutico e de cura (Martins e Peixoto Junior, 2009). Para Foucault (1978/1998; 1976/2014), esse processo de medicalização tornou-se possível exatamente pela introdução dos mecanismos disciplinares no espaço hospitalar, até então desordenado, e pela extensão da prática da medicina aos problemas do ambiente, quando a doença passou a ser considerada um fenômeno que obedecia a leis naturais (Martins e Peixoto Junior, 2009). Dessa forma, o hospital moderno impregnou-se de concepções biomédicas, sendo socialmente legitimado como local ideal para o exercício da medicina, juntamente pelo fortalecimento do ensino médico.

Nesse contexto de valorização dos dispositivos disciplinares e da medicina, também o nascimento e a morte, até então eventos circuncritos à esfera domiciliar, com forte carater familiar, passaram à esfera do hospital. Desse modo, foi enfim constituído como local privilegiado do saber-poder médico sobre os corpos de quem nasce e de quem morre.

Nesse sentido, vida e morte estão constantemente em jogo nos contextos de saúde, sendo as práticas e concepções sobre esses eventos refletidas diretamente na forma como cada pessoa vivencia o nascer, o adoecer e o morrer. E assim é que diariamente mulheres adentram aos locais de nascimento para dar à luz, e diariamente muitas delas entram em UTIN para estar com seus bebês.

Muitos têm sido os avanços propiciados pela problematização da hegemonia do modelo biomédico tanto na forma de lidar com o nascimento quanto com a morte. Isso pode ser visto historicamente nos movimentos sociais de mulheres pelo direito de escolha no momento do parto, na luta pelo protagonismo de suas próprias experiências. No cenário do adoecimento e da morte, igualmente, é possível observar um movimento contra essa hegemonia e o controle da medicalização, que se expressa na mobilização pela prática dos cuidados paliativos, pelo direito dos pacientes com doenças sem 
possibilidade de cura e de suas famílias de serem ouvidos e terem a possibilidade de fazer escolhas nesse momento.

Nesses dois polos o ponto central é a pessoa que está atravessando esse processo e a garantia ou ausência de seus direitos. No Brasil, a partir da redemocratização e da promulgação da Constituição de 1988, que criou o Sistema Único de Sáude (SUS), a construção das políticas de saúde passou a ser alicerçada nos direitos e no protagonismo dos/as usuários/as, na valorização de suas vozes e nas práticas de cuidado fundamentadas no conceito da integralidade (Merhy, 2000; Mattos, 2001). Entretanto, mantém-se o desafio de colocar em prática no cotidiano dos serviços de saúde a atenção integral e, ao mesmo tempo, garantir direitos aos/às usuários/as, por meio dos encontros que cada interação de cuidado possibilita nos diversos cenários da saúde.

Partimos do pressuposto de que o nascimento e a morte são eventos biopsicossociais, o que implica considerar toda a complexidade que os envolvem. Assim, entendemos que cada contexto de cuidado é capaz de mostrar diferentes realidades, à medida que este é construído de forma dinâmica por uma rede que integra e correlaciona diferentes atores, artefatos, práticas, saberes e perspectivas sobre o nascer e o morrer. Fazer pesquisa sobre essas temáticas é envolver-se com uma parte fundamental e íntima da história de vida de cada pessoa que compartilha conosco um pouco de suas trajetórias, de suas alegrias, suas frustrações, seus dilemas e suas tristezas.

Feita essa consideração preliminar, importane dizer que este artigo filia-se à abordagem construcionista da pesquisa no cotidiano (Spink, 2003), para a qual os encontros e as conversas que ocorrem no campo produzem aprendizados tanto para o/a investigador/a como para os participantes da investigação científica. Essa dinâmica faz do ato de pesquisar uma ação colaborativa que envolve pessoas, materialidades, instituições e grupos, exigindo reflexões e posicionamentos éticos constantes acerca das nossas posturas e posições antes, durante e depois da pesquisa (Brigagão, 2016). Daí a importância de evidenciar no projeto de pesquisa a subjetividade do próprio pesquisador (Tornquist, 2004).

Sob essa abordagem, apresentamos neste manuscrito excertos dos diários de campo produzido pela primeira autora, bem como das entrevistas com participantes das pesquisas realizadas em serviços de atenção ao parto e uma unidade de terapia intensiva neonatal, vinculados ao SUS. Entendemos que ao dar voz aos sujeitos da investigação ampliamos a discussão sobre as práticas e relações de cuidado presentes nos contextos estudados. 
É importante ressaltar que os trabalhos que deram origem à presente reflexão foram aprovados por comitê de ética ${ }^{1}$ em pesquisa e atenderam às recomendações relativas às pesquisas com seres humanos do Conselho Nacional de Saúde (CNS). Durante todo o processo investigativo foram respeitados os princípios éticos da autonomia, ou seja, o direito da pessoa de decidir sobre sua participação, mediante assinatura do Termo de Consentimento Livre e Esclarecido. Os nomes de participantes que aparecem neste trabalho são fictícios, de modo a preservar o seu anonimato.

\section{Nas tessituras da investigação do nascer e adoecer}

Para relatar as experiências de campo, tomamos como ponto de partida a compreensão de Mary Jane Spink (2003), para quem o campo da pesquisa social é, sobretudo, uma forma de narrar o mundo. Ou seja, ela é tanto uma produtora social de relatos quanto uma forma de contar e produzir o mundo. Nesse entendimento, investigar é contar histórias que estão inseridas em uma rede de componentes heterogêneos que produzem saberes e reflexões. Assim, a pesquisa é construída por processos dialógicos entre o/a pesquisador/a e os/as participantes que, ao se posicionarem, negociam e compartilham as suas visões de mundo (Brigagão, 2016; Spink, 2003).

Os microlugares nos quais convivemos e que se constroem dentro e fora do/a pesquisador/a passam a constituir o campo. Nessa perspectiva, o campo é mais do que um território delimitado e apresenta muitas faces (Spink, 2003). Ele é uma processualidade de temas situados; um complexo de redes de sentidos que se interconectam; um espaço criado, herdado ou incorporado pelo pesquisador, por meio de debates e negociações em que busca se inserir em teias de ação, dentro de um processo que também tem lugar e tempo (Spink, P., 2008). Por seu caráter processual e por ser atravessado por questões de poder, morais, políticas, teóricas e culturais, o campo é um campo-tema. Essa noção refuta radicalmente a ideia da não neutralidade como um problema para a pesquisa social; ao contrário, a subjetividade do/a pesquisador/a é entendida como mais um recurso do processo investigativo (Cordeiro et al., 2014).

Desse modo, podemos dizer que o nosso interesse sobre a presente temática foi se construindo a partir das nossas próprias experiências cotidianas (cenas de nascimento presenciadas, histórias de parto contadas pelas mulheres da nossa prórpia rede, participação em eventos acadêmicos e políticos), bem como da necessidade e do desejo de ouvir e dar voz às pessoas que intengram o cotidiano de hospitais, em geral silenciadas.

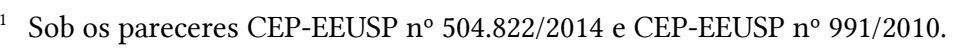


Aproximando-nos do conceito ontológico da praxiologia problematizado pela filósofa Annemarie Mol (2002), podemos compreender porque as experiências de campo são um processo construído por uma rede de interações entre atores, artefatos, teorias e subjetividades e que faz a realidade ser múltipla. Aos investigar as tensões entre fontes e estilos de conhecimento, a autora demonstrou como esses são manipulados no cotidiano da medicina alopática. Seu foco não foi a interação entre médico e paciente, mas sim as normas que regulam essa relação; tampouco buscou as diferentes perspectivas dos atores. Ao voltar seu interesse para a compreensão de como os saberes e os objetos são manipulados nas práticas médicas e como estas se diferenciam entre si, Mol (2002) definiu a realidade como múltipla. Em outras palavras, os conhecimentos não são compreendidos como modos de referência, mas sim como uma manipulação. O foco está no conhecimento da prática e como os objetos não são os mesmos de um lugar para o outro. É dizer, existem diferentes versões de um mesmo objeto, possuidores de um mesmo nome, que ora divergem em confronto, ora são interdependentes.

Para Mol (2002), a realidade como parte da prática é um ato, uma intervenção. Isso sucede nos diferentes estilos disponíveis para descrever as práticas. Ao apontar que a realidade é múltipla, a autora postula que esta não precede a prática, mas é parte dela. Nesse sentido, as realidades são sociomateriais e, por isso, diferentes ontologias informam sobre os nossos corpos, a organização do nosso sistema de saúde, o ritmo e as dores das nossas doenças, assim como o formato das nossas tecnologias. Todos esses componentes estão entrelaçados em tensões. E, se a realidade é múltipla, ela também é política.

Nessa perspectiva, é possível dizer que no nascimento as formas de cuidado e de intervenções típicas do sistema biomédico refletem-se nos corpos das mulheres e passam a performar esse evento. Essa realidade aparece nas histórias de dor, na escuta dos gritos, no aperto das mãos, na água quente caindo sobre a lombar e o ventre, nos cor pos grávidos colocados em macas estreitas, nos pedidos de ajuda, no corte profundo no períneo, nas diferenças sociais que transparecem em cenas e falas:

Você não pode chorar, nem respirar. A médica falou que tinha combinado comigo para eu não incomodar as outras pacientes. E quando eu começava, elas já vinham: "Não chora!" (Vanda, entrevista pessoal, abril 2012)

Outro dia eu cheguei lá e me sentei. Mas mulher grávida não fecha as pernas... a enfermeira falou: "Fecha as pernas, minha filha! Foi desse jeito que você engravidou, de viver com as pernas abertas". (Ada, entrevista pessoal, maio 2012) 
"Faz força como se você fosse fazer cocô". Mas a mulher que estava fazendo o parto já estava um pouco sem paciência. Ela falava: "Faz força direitinho, colabora com a gente". Mas era isso que eu falava: "Não sou eu que não consigo, é meu corpo que não vai". A médica falou: "Você tem que fazer força, colocar o bebê para fora!" Mas a dor de colocar o bebê para fora não vinha; eu não sentia essa dor. Eu fiz uma última força e saiu a cabeça. Aí eu travei a perna. Ela falou: "Você quase machucou seu bebê, viu, mãezinha?" Você sai dali só o bagaço, costurada. (Rita, entrevista pessoal, maio 2012)

Esses excertos também evidenciam a dimensão de gênero e de violação dos direitos sexuais e reprodutivos da mulher no trabalho de parto e parto tributários do modelo biomédico. Nele, é produzido um cuidado que reduz a mulher ao seu ventre/útero e torna a experiência do nascimento mera ação fisiológica.

Ocorre que, para a gestante, a dor da contração tem um sentido diverso daquele que ela vai experimentar depois de adentrar as portas da instituição hospitalar. É ali que essa dor ganha novos significados, inclusive definindo o itinerário que cada mulher percorrerá ao longo do trabalho de parto e do parto: cadeiras, mesas, maca, sonar, banqueta, bola, chuveiro, soro, protocolos... Em meio à miríade das tecnologias do nascimento, o evento ganha forma. E, assim, as práticas e as relações de cuidado são construídas, modificando-se em meio a materialidades e atores que compõem a cena.

A médica entrava na sala e falava: "Hoje eu quero estourar uma bolsa!” E eu só pensava: "Tomara que não seja a minha." (Vanda, entrevista pessoal, abril 2012)

Eles fizeram o toque e estourou a bolsa... foi com um negócio [rompedor de membrana amniótica]. Eu fiquei até meio assim, porque não foi só a mão e ela não falou nada. Eu já fui para o quarto andando; eles colocaram o soro $\mathrm{e}$ um comprimido. Eu fiquei das duas da tarde até as onze horas da manhã do outro dia e ninguém fazia nada! (Ada, entrevista pessoal, maio 2012)

Me levaram para a sala do pré-parto e, chegando lá, elas me deram o soro. Fiquei no soro e a dor começou a ficar forte. Tudo que elas vinham fazer eu perguntava para o que era, mas elas não falavam que o soro era para dar dor. (Amanda, entrevista pessoal, junho 2012)

Tinha uma que queria que eu ficasse uma hora debaixo da água. E eu sem aguentar de tanta dor! Mas elas me deixavam lá e saíam e eu gritava, porque não estava aguentando ficar. E elas falavam que eu tinha que ficar, tinha que ficar. (Ada, entrevista pessoal, maio 2012) 
Dessa mesma forma, a doença de um bebê recém-nascido é produzida nos discursos intensivistas, a partir de explicações diagnósticas, de resultados de exames laboratoriais, dos protocolos, das avaliações clínicas; nos prognósticos apresentados aos pais, na tetralogia de Fallot explicada através de um desenho em que o coração é como um grande tanque por onde a água deve ser bombeada; na administração de fármacos, na nutrição parenteral, nos tubos, nos sensores, nos sons e nos números de saturação e frequência cardíaca.

Com base na problematização proposta por Annemarie Mol, podemos dizer que o nascimento e a doença apresentam-se através de uma rede de materialidades em que tempos e lugares são capazes de nos mostrar diferentes realidades. Nessa dinâmica, saberes diversos estão impressos nas práticas e, assim, ingredientes heterogêneos tomam a cena: palavras, mãos, tecnologias, organizações. Estamos diante de diferentes contextos de cuidado, de vivências singulares, profissionais singulares, mulheres singulares e bebês singulares. Estamos diante da realidade múltipla e complexa que envolve o nascimento, o adoecimento e a morte.

\section{Uma mãe conta o parto, uma mãe conta o luto}

\section{Um dia e o resto de nossas vidas... A história de Rita}

A realidade complexa aparece entrelaçando histórias do nascer e morrer. Em uma pesquisa sobre os contextos de cuidado ao parto, nos deparamos com o inesperado, com a morte e o modo como ela permeia a vida.

Rita estava grávida do seu segundo filho; disse que quando seu bebê nascesse iria contar como fora o parto. Antes, falou:

Preciso te contar outra história antes... é um dia e o resto de nossas vidas: depois do nascimento tudo muda... O parto foi o momento mais importante. É amor acima de tudo, é garra, muita força. Ele foi a experiência mais forte da minha vida, mas, em seguida, eu tive outra [experiência]. Então eu não consigo dar um sentido mais forte para o parto diante da perda. O parto em si é muito amor, mas ele não tinha nem um mês quando eu descobri o câncer... O Joaquim nasceu em abril de 2010. E quando ele fez 27 dias, no Dia das Mães, eu descobri a doença dele [choro]... eu perdi o equilíbrio... Eu sou muito disso que aconteceu: $90 \%$ do que eu sou hoje é dessa experiência para frente. (Rita, entrevista pessoal, junho de 2011)

Ela relatou sua história aos poucos. Com lágrimas nos olhos, nos contou como Joaquim veio ao mundo e como ele morreu. Foi possível conhecê-lo através das lembran- 
ças - fotos na geladeira, pela casa; seu nome tatuado na pele de Rita. O bebê nasceu após horas de um trabalho de parto cansativo, exaustivo, mas, para a mãe, transformador, em cada detalhe. A maternidade, que começou a ser construída durante a gestação, no corpo, nos desejos, nos sonhos, foi contínua e não cessou. E assim como o parto, a morte também mudou a sua vida.

Uma vez que você deseja ser mãe, você já é. Porque você prepara seu corpo para isso, você prepara sua vida. A gente já começa ser mãe quando a cabeça está preparada para isso, antes mesmo da concepção. Isso é muito forte, intenso, porque a gente ganha outra vida. Isso tudo dividiu minha vida. Não do jeito que eu gostaria, porque a gravidez é um divisor; o parto é outro; a criança é outro. Acho que foi divisor extra [a morte do filho], mais uma página para virar. (Rita, entrevista pessoal, junho de 2011)

Em conversa informal dias após a entrevista, Rita contou detalhes do que viveu: o processo de quimioterapia, o aprendizado sobre as dosagens, nomes de fármacos e a interpretação dos sinais de dor. Falou das dificuldades enfrentadas no ambiente hospitalar e como essa experiência modificou a sua vida, a ponto de decidir tornar-se enfermeira. Mas ela precisou de tempo para contar sua história, o que demonstra que pesquisar assuntos como morte e luto exige do/a pesquisador/a escuta ativa e acolhimento, de modo que a pessoa sinta-se à vontade para falar da sua experiência.

A sensibilidade do/a pesquisador/a é essencial para lidar com um assunto tão íntimo e intenso, como a morte. E é ouvindo histórias como essa que aprendemos que as experiências de nascer e morrer, aparentemente em pontos opostos do curso da vida, podem se cruzar.

Entre bips, incubadoras e fármacos: um colo para o bebê, um espaço para a mãe

Estar em um ambiente não familiar, sobretudo no hospital, é experimentar a sensação de que o mundo parou e uma nova noção de tempo nos foi imposta. É o que diz Camila Goytacaz (2015) ao compartilhar a sua experiência no livro Até breve, José, que os sons da UTIN são mais fortes que os sons da rua, e assim o mundo continua a girar, mas e a mãe como está? Morrendo também: com fome, com sede, cansada.

A história de Rita nos faz refletir acerca do quão pouco conversamos sobre o adoecimento e a morte de um bebê, e como suas mães, seus pais, suas famílias vivenciam cotidianamente as situações de doença e perda. Considerando que vivemos em uma sociedade que valoriza constantemente a conquista e que a morte é vista como derrota e falência, esse é um assunto velado, não raro interditado. Quando não há dialogo e es- 
paço para compartilhar o luto, o processo se torna ainda mais difícil e solitário. E isso se impõe como um grande desafio para os profissionais da saúde que lidam com a doença e com a morte cotidianamente (Silva et al., 2017).

Mas quando esses eventos atingem um bebê, vivemos uma espécie de violação: de expectativas e de um futuro cheio de planos. Porque quebra a normalidade do curso da vida, conversar sobre morrer é entrar no campo dos assuntos proibidos. O que faz esse processo ser árduo, carregado de culpa (Davis, 1996, pp. 1-3).

Estar numa UTI neonatal para realizar um estudo é reconhecer a importância desse tema para a atenção em saúde. Isso porque o acesso a quem vive essa experiência mães e familiares - é fundamental para o desenvolvimento de estratégias humanizadas de cuidado.

Mas é preciso admitir: esse não é um processo simples. Entrar nesse campo significa, ao mesmo tempo, nos depararmos com muitos medos e desafios.

Durante o processo de estar no campo, eu entrei em contato com histórias de mulheres em livros, documentários, eventos científicos; com a história da minha própria mãe que perdeu dois filhos precocemente. Imersa nessa reflexão entrei na UTIN e passei a frequentar o grupo de pais, que acontecia semanalmente, até conseguir entrar propriamente no espaço onde moram os bebês e passam a morar suas famílias; onde moram nomes estranhos e sons de "bips". Eu precisei de um tempo para vencer meus próprios receios e para me aproximar da equipe. Percorri o mesmo trajeto das mães, toquei a campainha para ser autorizada a entrar, lavei bem as mãos conforme a regra do cartaz, coloquei o avental azul e entrei. Meu coração sempre acelerava, a distância até os leitos parecia mais longa do que era na realidade. No primeiro dia eu conheci os bebês que eu tanto ouvia falar nas reuniões de pais. Vivenciar isso trouxe para mim a realidade do que era discutido no grupo: tubos, diálise, cateteres, diversos fármacos, sedativos e mães, mães ao lado dos berços e incubadoras. (Entrada de diário de campo, maio de 2015)

Pegar um bebê no colo, coisa tão corriqueira para tantas mães, pra gente é um prêmio-Fala de uma mãe em reunião entre profissionais e pais. (Entrada de diário de campo, maio de 2015)

Ser mãe de um bebê doente é um desafio constante. Muitas mães na UTIN viajam longas distâncias para visitar seus filhos. Uma delas, vinda da Bahia, decidiu que ficaria na UTIN. Ela aparentava cansaço. Durante a reunião, a médica passou informações sobre o estado da bebê, que era muito grave, acrescentando que achava que a mãe estava um pouco perdida em relação ao quadro de saúde da filha. Mas estava enganada: "Eu sei que é grave. Ela está aqui há quatro meses! Eu tô ficando aqui porque não consigo 
dormir só.” A profissional insistiu que a mãe dormir na UTIN era desconfortável; ela respondeu que preferia ficar.

Esse episódio deflagrou um questionamento acerca do cuidado medicalizado: como dar atenção às inumeras demandas de mães que veem suas vidas mudar no enfrentamento cotidiano dos desafios que surgem diante de um bebê doente? A reação da médica dá mostras de que a engrenagem dos sistemas de saúde muitas vezes impede o olhar e a produção de um cuidado e de práticas que ultrapassem o fluxo protocolar e permitam trocas intersubjetivas.

No contexto tributário do modelo biomédico, a comunicação entre mães e profissionais da UTI é igualmente problemática. Isso porque está assentada em um modelo unidirecional de transmissão de informações, instituidor e mantenedor de relações au toritárias, prescritivas e normatizadoras, que toma o sujeito como mero receptor da informação, como um ser vazio que deve ser preenchido por quem detém o conhecimento perito (Freire, 1996). É o que se depreende dos excertos a seguir:

O médico falou que meu filho é como um bolo solado. Sabe aquele bolo que solou, que não deu certo? Você não tem mais nada para fazer para o bolo melhorar, para ficar bom. -Conversa com uma mãe na sala de espera da UTI (Entrada de diário de campo, maio de 2015)

Os médicos falam nome de remédio que eu não sei nem o que é. Sedaram ela, ela ficou muito nervosa. Eles falaram era que ia trocar o cateter dela. Eu cheguei aqui e eles me barraram, pediram para eu ficar lá fora... eu fiquei preocupada. Eu tô angustiada (...) se eu for discutir com os médicos eles vão falar que eu não estudei, que eu não sei de nada , que eu não posso dar opinião. $\mathrm{E}$ eles já estão fazendo demais, que é ajudar minha filha. (Débora, entrevista pessoal, maio de 2015)

Ocorre que ser mãe de um bebê doente não significa apenas lidar com as angústias do dia a dia. Para essas mulheres, estar numa unidade de terapia intensiva implica também aprendizados: aos poucos elas aprendem a identificar sinais de dor e a distinguir os sons emitidos pelo monitor.

Você chega e vê o filho de um jeito. Depois, quando vê, ele está totalmente diferente. Esse inchaço que ele tem não dá para explicar... só mãe mesmo para ver e sentir. (Entrada de diário de campo, maio de 2015)

Eu estou na gangorra com ele. Ele desce, eu desço; ele sobe, eu subo. (Entrada de diário de campo, maio de 2015) 
Eu quero saber quando ela está com dor, porque ela não sabe falar... Eu fico olhando o monitor, ele apita e ninguém vem. Eu não consigo ir embora e deixar minha filha aqui. (Entrada de diário de campo, maio de 2015)

A noção de indivíduo/pessoa de um bebê é construída socialmente, quando, ainda durante a gestação, a perspectiva de sua chegada altera as relações familiares; quando lhe é dado o um nome. O hospital, entretanto, muitas vezes impede o seu reconhecimento como pessoa, reduzindo-o à substância e à doença (Machado, 2013). Essa concepção medicalizada reflete-se diretamente na forma como mães, pais e família relacionam-se com seus bebês durante a internação.

Certo dia, na UTIN, uma profissional da equipe pediu para que eu conversasse com uma mãe. Ela falou: "Você é a psicóloga, conversa com uma mãe que está para chegar, por favor?” Isso gerou em mim sentimentos paradoxais: ao mesmo tempo que eu estava conseguindo aproximação com a equipe, senti um incomodo. O fato de estar ali, parar e conversar com as mães fez de mim psicologa. $\mathrm{O}$ ato de fazer essa conversa parece pertencer exclusivamente a esse ator/atriz psicológo(a). Por que não existe tempo/espaço para que outros(as) atores/atrizes do cuidado componham esse lugar de escuta e troca? (Entrada de diário de campo, maio de 2015)

Desse cenário emergiu um questionamento: como encontrar um espaço para chorar e para ser ouvida em meio ao cotidiano agitado e carregado de uma unidade de terapia intensiva? Como ser mulher, mãe naquele ambiente impessoal, que paradoxalmente passa a ser a casa todos. Muitos fatores estão em jogo na possibilidade de achar um espaço para chorar e compartilhar sentimentos. Durante uma conversa com uma mãe, momentos antes da reunião de familiares para discutir o quadro de saúde dos seus bebês, ela desabafou:

Eu estou cansada. Faz três meses que estou aqui, estou no meu limite. [choro...]. Eles [equipe da UTI] falam: "Mãezinha, não chora..." Mas não tem como! Eu não posso chorar que querem que eu fale com o psicólogo. Eu não quero falar com o psicólogo! (Entrada de diário de campo, maio de 2015)

Maria Auxiliadora Craice de Benedetto et al., (2011) observam que, para a medicina, o ato de ouvir pacientes para além de suas histórias clínicas é um ofício de psicólogos. Isso sinaliza que a formação de médicos não visa a suprir habilidades psicoterapêuticas. Nessa linha, as autoras apontam: quando os pacientes e suas famílias encontram profissionais dispostos a ouvir as suas histórias com empatia facilmente começam a compartilhar detalhes de suas trajetórias de vida, seus sofrimentos, suas crenças e seus paradigmas. Essas narrativas, quando valorizadas, além do reconhecido papel 
terapêutico, podem ser aplicadas em um plano de cuidado, levando à reflexão do verdadeiro cuidado integral.

Roubaram meu filho, levaram ele embora. (Rita, entrevista pessoal junho de 2011)

Meu anjinho foi para o céu. (Mensagem recebida pela primeira autora de uma participante da pesquisa, em maio de 2015)

A percepção da doença como contínua e sem fim altera escolhas, decisões e identidades. A morte do outro é a vivência da morte em vida. Nessa experiência uma parte de quem fica morre; aquela que estava ligada ao outro por laços afetivos (Frank, 1998; Kovács, 1992). O rompimento que a morte causa parece ser irreversível; a vida, o cotidiano parecem estar à sombra da perda.

Diante dessa morte, o luto configura-se como rito de passagem capaz de dar novo sentido à vida. Mas como dar vazão a essa experiência em uma sociedade em que os sentimentos e as manifestações do luto devem ser reprimidos? Não estamos preparados para lidar com a morte naturalmente, como condição inerente do viver. Assim, o adoecimento e a morte causam silenciamento; simbolicamente, é como se as pessoas que perdem e vivenciam o luto também perdessem suas próprias vozes.

Mas, postulam Benedetto, Vieira e Holanda (2011), as histórias de caos podem ser transformadoras, desde que se aprenda e se ensine com o evento doloroso. No caso da doença, as autoras lembram que a medicina baseada em evidência não pode ser praticada sem a medicina baseada em narrativa:

Existe espaço para histórias tão humanas em um mundo dominado pela alta tecnologia, em que procedimentos, diagnósticos e terapêuticos sofisticados assumem o primeiro plano e são considerados essenciais para uma boa prática da medicina? O que fazer quando a tecnologia não pode mais oferecer soluções? (...) No dia a dia, médicos e profissionais da saúde se defrontam com pessoas únicas e especiais, que vivenciam sua doença de forma particular... para se obter bons resultados clínicos é necessário adequar as evidencias cientificas ao contexto individual. (Benedetto et al., 2011, p. 24)

Para isso é preciso ouvir histórias e aprofundar o conhecimento, o que só acontece através das trocas entre profissionais e pacientes. Pesquisar no campo do nascimento e da morte é importante para que mudanças sejam articuladas e a criação de novas estratégias de atenção à saúde sejam promovidas. Torna-se essencial, no cenário atual dos contextos de cuidado, reconhecer e agir em prol da escuta profunda, a partir da qual práticas de cuidado possam ser produzidas com base nas ações integrais de saúde, inclusive nas relações com familiares em situação de morte. 


\section{Conclusão}

Nas experiências de pesquisa que lidam com o nascimento e a morte, percebemos como cada contexto se manifesta como um caleidoscópio de práticas de saúde que se movimenta e rearranja dinamicamente, formando diferentes cenas. Trazer as mulheres, as família e os bebês para o centro da cena do cuidado é reconhecer os sentidos que constituem cada vivência e as suas implicações na vida das pessoas (Salim et al., 2017).

Precisamos ouvir e não silenciar as vozes das pessoas que vivenciam histórias de nascimento, adoecimento e luto, para assim aprender com elas a produzir um outro cuidado. Esse foi o grande aprendizado que as investigações aqui relatadas proporcionaram.

Elas também permitiram refletir sobre a importância da abertura de espaços de escuta nos serviços de atenção à saúde como forma de assegurar a emergência da subjetividade dos processos de nascer, de morrer e de luto. A escuta ativa e o acolhimento são parte do fazer em saúde e, como tal, devem sustentar continuamente as ações com vistas à humanização dos serviços, possibilitando espaços de trocas, de aprendizado, de vivências para familiares, profissionais, mulheres e bebês. No contexto da pesquisa social, ouvir essas experiências e trazer os sentimentos vivenciados e as necessidades das pessoas ajuda a pensar em práticas que possibilitem a produção do cuidado em saúde integral.

Para Emerson Elias Merhy et al. (2010), essa escuta ativa é o encontro genuíno com o sofrimento do outro, e o que de fato permite a produção de formas de acolhimento. Este, por sua vez, só acontece por meio da construção de uma rede que atue para a produção do cuidado pautado na integralidade, rompendo com as estruturas de uma prática que se distancia da pessoa, de sua história, superando a dinâmica que reduz e confina os/as usuários/as dos serviços de saúde ao seu aspecto biólogico.

\section{Agradecimento}

Agradecimentos e Dedicatória da Primeira autora:

Dedico esse relato à memória de Synezia Lourenço Barbosa, Mauro Fernando Salim e Paulo César Barbosa, que com suas partidas me fizeram rever a vida. Saudades.

À Aurora, a bebê de cinco meses internada na UTIN que sorriu para mim enquanto eu cantava para ela, jamais vou esquecer seu rosto. Dedico à sua mãe, que caminha- 
va entre esperança e desesperança... Dedico à Rita e à todas as mães e pais que se tornaram e tornam-se órfãs todos os dias.

Às professoras Dulce M. Rosa Gualda e Jacqueline Isaac Machado Brigagão, por serem inspiração sempre.

\section{Referências}

Benedetto, Maria Auxiliadora Craice de; Vieira, Nádia Vitorino; Holanda, Fabíola (2011). Narrativas em saúde: um recurso para lidar com a dor, o sofrimento e a morte. Oralidades - Revista de História Oral, 5(10), 17-30. https://www.revistas.usp.br/oralidades/article/view/107244/105761

Brigagão, Jacqueline Isaac Machado (2016). Aspectos éticos nas pesquisas no cotidiano. Athenea Digital, 16(2), 363-372. https://doi.org/10.5565/rev/athenea.1842

Cordeiro, Mariana P.; Freitas, Tiago R.; Conejo, Simone P.; Luz, George M. (2014). Como pensamos ética em pesquisa. In: Mary Jane Paris Spink, Jacqueline Isaac Machado Brigagão, Vanda Lúcia Vitoriano do Nascimento \& Mariana Prioli Cordeiro. (Orgs.). A produção de informação na pesquisa social: compartilhando ferramentas (pp. 31-56). Centro Edelstein de Pesquisas Sociais.

Davis, Deborah L. (1996). Empty cradle, broken heart: surviving the death of your baby. FulcrumPublishing.

Freire, Paulo (1996). Pedagogia da autonomia. Paz e Terra.

Foucault, Michel (1978/1998). O nascimento do hospital. In: Microfísica do poder (p. 7998). Edições Graal.

Foucault, Michel (1976/2014). História da sexualidade (v. 1): a vontade de saber. Paz \& Terra.

Frank, Arthur W. (1998). Just listening: narrative and deep illness. Families, Systems, \& Health, 16(3), 197-212.

Goytacaz, Camila (2015). Até breve, José. Dita Livros.

Illich, Ivan (1976). Medical nemesis: the expropriation of health. Random House.

Kovács, Maria Júlia. (1992). Morte e desenvolvimento humano. Casa do Psicólogo.

Machado, Igor José de Renó (2013). O inverso do embrião: reflexões sobre a substancialidade da pessoa em bebês prematuros. Mana, 19(1). https://doi.org/10.1590/S0104-93132013000100004

Martins, Luiz Alberto Moreira \& Peixoto Junior, Carlos Augusto (2009). Genealogia do biopoder. Psicologia \& Sociedade, 21(2). https://doi.org/10.1590/S0102$\underline{71822009000200002}$

Mattos, Ruben Araújo (2001). Os sentidos da integralidade: algumas reflexões acerca de valores que merecem ser defendidos. In: Pinheiro, Roseni; Mattos, Ruben de Araújo (Org.). Os sentidos da integralidade na atenção e no cuidado à saúde (pp. 39-64). Rio de Janeiro: UERJ/IMS:Abrasco. 
Merhy, Emerson Elias (2000). Um ensaio sobre o médico e suas valises tecnológicas: contribuições para compreender as reestruturações produtivas do setor saúde. Interface - Comunicação, Saúde, Educação, 4(6), 109-116. https://doi.org/10.1590/S1414-32832000000100009

Merhy, Emerson Elias; Feuerwerker, Laura C. M.; Cerqueira, Maria Paula (2010). Da repetição à diferença: construindo sentidos com o outro no mundo do cuidado. In: Tulio B. Franco \& Valéria do Carmo Ramos (Orgs.), Semiótica, afecção \& cuidado em saúde (pp. 60-75). Hucitec.

Mol, Annemarie. (2002). The bodymultiple: ontology in medical practice. Duke University Press.

Rohden, Fabíola (2006). Sexualidade e gênero na medicina. In: Alicia N. Souza \& Jaqueline Pitanguy (Orgs.), Saúde, corpo e sociedade (pp. 157-180). UFRJ.

Salim, Natália Rejane; Gualda, Dulce Maria Rosa \& Soares, Glauce Cristina Ferreira (2017). Vivendo o parto: diferentes realidades, diferentes contextos. In: Dulce Maria Rosa Gualda, Edemilson Antunes de Campos, Glauce Cristiane Ferreira Soares, Natália Rejane Salim, Neide de Souza Praça (Org.). Nascimento: perspectivas antropológicas (pp. 165-191). Ícone.

Silva, Isabella Navarro; Salim, Natália Rejane; Szylit, Regina; Sampaio, Patricia Stella Silva; Ichikawa, Carolliny Rossi de Faria; dos Santos, Maiara Rodrigues. (2017). Conhecendo as práticas de cuidado da equipe de enfermagem em relação ao cuidado na situação de final de vida de recém-nascidos. Escola Anna Nery, 21(4), e20160369. https://doi.org/10.1590/2177-9465-ean-2016-0369

Sousa, Noelma C. De \& Meneses, Antonio B. N. T. De (2010). O poder disciplinar: uma leitura em vigiar e punir. Saberes: Revista interdisciplinar de Filosofia e Educação, 1(4). 18-35 https://periodicos.ufrn.br/saberes/article/view/561

Spink, Mary Jane (2003). Psicologia social e saúde: práticas, saberes e sentidos. Vozes.

Spink, Peter K. (2008). O pesquisador conversador no cotidiano. Psicologia \& Sociedade, 20(n.spe), 70-77. https://doi.org/10.1590/S0102-71822008000400010

Tornquist, Carmen Susana (2004). Parto e poder: o movimento pela humanização do parto no Brasil. Tese de doutorado inédita. Universidade Federal de Santa Catarina, Florianópolis.

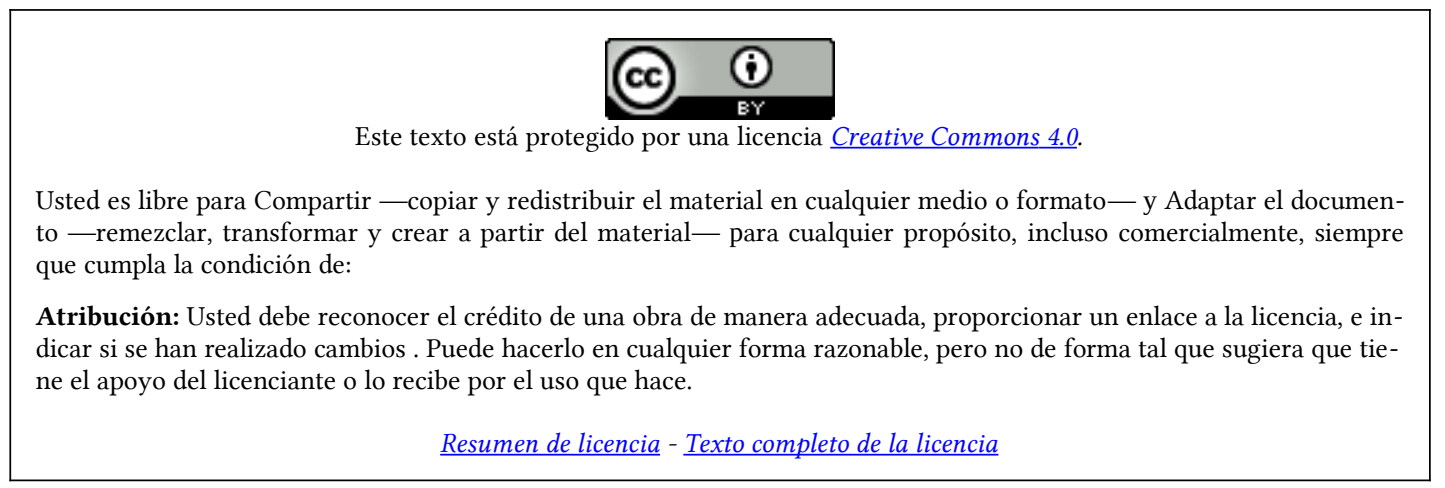

